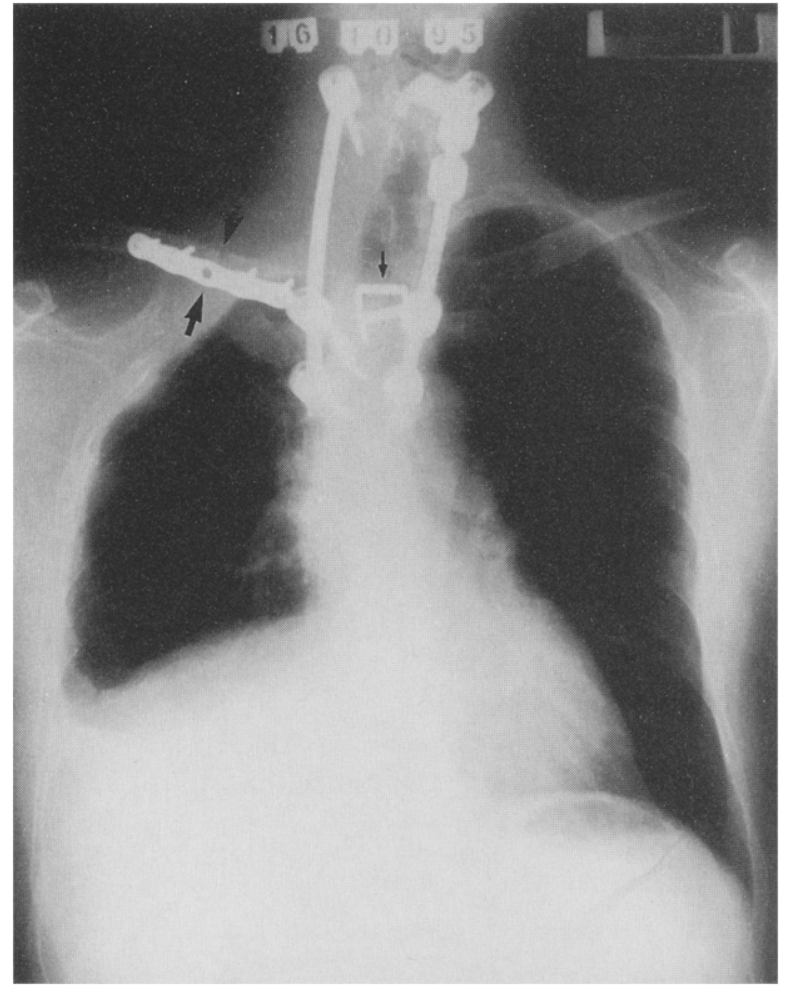

Fig. 1. Chest x-ray film of a 42-year-old man operated on in May 1995. He had a 12-month history of C8-T1 pain related to a right upper lobe tumor invading the ispilateral T1-2 intervertebral foramen, respective hemivertebrae, and head of the first three ribs. A combined transclavicular and median posterior approach was used. The tumor was completely removed en bloc with the first three right thoracic hemivertebrae and spinal nerves and ribs' posterior arches. Spinal stabilization was then made bilaterally. Considering the postoperative risks of chest wall instability and need of mechanical ventilation, the clavicle was not disarticulated, but an oblique section of the manubrium was made to fully preserve the sternoclavicular articulation. Clavicular osteosynthesis was then obtained by placing one metallic wire across the lateral and medial clavicle (arrows) and two across the divided manubrium (small arrow).

discomfort. Thus, given the prognosis of the underlying disease, the risks of pseudoarthrosis after clavicular osteosynthesis, and the fact that resection of the clavicle alone has no cosmetic or functional repercussions, our opinion is that routine preservation of the clavicle is unnecessary.

Osteosynthesis of the clavicle should be the exception and not the rule. If one wishes to restore the sternoclavicular joint with the aim of improving chest wall stability, the best technique would be an oblique section of the manubrium (Fig. 1) that fully preserves the sternoclavicular articulation, its intraarticular disk, and the costoclavicular ligaments (which mainly contribute to the shoulder girdle stability) instead of simple disarticulation of the clavicle from the sternum.

We disagree with the statement that pulling the disarticulated clavicle downward yields an equally wide surgical field. Inevitably, as Nazari's experience increases, he will be faced with more extensive tumors of the thoracic inlet than those described in his two case reports. Having a well-exposed operative field is safer both for the surgeon and for the patient.

$$
\begin{array}{r}
\text { Philippe G. Dartevelle, MD } \\
\text { Paolo Macchiarini, MD } \\
\text { Department of Thoracic and Vascular Surgery } \\
\text { and Heart-Lung Transplantation } \\
\text { Marie-Lannelongue Hospital } \\
92350 \text { Le Plessis-Robinson, France }
\end{array}
$$

$12 / 8 / 73100$

\section{Human cytokine responses to cardiac operations: Prebypass factors \\ To the Editor:}

We congratulate Wan and colleagues ${ }^{1}$ for their interesting article, "Human Cytokine Responses to Cardiac Transplantation and Coronary Artery Bypass Grafting." They suggested that the interleukin-10 response in elective coronary artery bypass graft and heart transplant operations formed part of a protective antiinflammatory response to cardiopulmonary bypass (CPB). We are delighted to see that researchers are now evaluating the balance of proinflammatory and antiinflammatory cytokine activity during cardiac operations.

A phased antiinflammatory response has already been demonstrated at elective coronary bypass operations. This response consists in a significant increase in plasma interleukin-10 concentration 10 minutes after release of the aortic crossclamp, reaching a peak 2 hours later. ${ }^{2}$ Lagging slightly behind the interleukin-10 response is an increase in plasma interleukin-1 receptor antagonist, which becomes significant 2 hours after CPB. Twenty-four hours later, concentrations of interleukin-10 and interleukin-1 receptor antagonist have returned almost to baseline levels, but there is a significant increase in plasma-soluble tumor necrosis factor receptors. This phased antiinflammatory cytokine response has also been demonstrated during pediatric cardiac operations. ${ }^{3}$

Small but significant pre-CPB increases in proinflammatory cytokine concentrations after induction of anesthesia with high-dose fentanyl and after heparinization have been described. Immediately after commencement of CPB these proinflammatory cytokine levels fall to baseline, possibly as a result of hemodilution. ${ }^{2}$ It would have been interesting in Dr. Wan's study to know whether induction of anesthesia alone with sufentanil and midazolam and later heparinization were associated with increases of differing magnitudes in the levels of proinflammatory cytokines in both groups. Such a difference between groups may exist, as indicated by the higher preheparinization interleukin-8 level in the transplant group. It is also possible that differing proinflammatory cytokine levels prime the immune system before CPB and 
result in a differing magnitude of antiinflammatory cytokine responses later. ${ }^{2}$ Without sampling before and after induction of anesthesia, this phenomenon is not detected.

W. T. McBride, $M D$

J. V. Booth, $M D$

Department of Anesthesiology

Duke University Medical Center

Durham, NC 27710

\section{REFERENCES}

1. Wan S, Marchant A, DeSmet J-M, Antoine M, Zhang H, Vachiery $\mathrm{J}$-L, et al. Human cytokine responses to cardiac transplantation and coronary artery bypass grafting. $\mathrm{J}$ Thorac Cardiovase Surg 1996;111:469-77.

2. McBride WT, Armstrong MA, Crockard AD, McMurray TJ, Rea JM. Cytokine balance and immunosuppressive changes at cardiac surgery: contrasting response between patients and isolated CPB circuits. Br J Anaesth 1995;75:724-33.

3. McBride WT, Armstrong MA, Gilliland H, McMurray TJ. The balance of pro and anti-inflammatory cytokines in plasma and bronchoalveolar lavage (BAL) at paediatric cardiac surgery. Cytokine. In press.

$12 / 8 / 74331$

\section{Reply to the Editor:}

We appreciate these comments regarding our recent article, ${ }^{1}$ which raise an important question about the triggering mechanism of cytokine responses after clinical cardiopulmonary bypass (CPB). Our previous study ${ }^{1}$ was not designed to evaluate "pre-CPB factors," so that cytokine levels were not compared before and after induction of anesthesia. It is true that interleukin- 8 values before heparinization were somewhat higher, although nonsignificantly and still at a very low level, in patients having heart transplantation than in those who underwent coronary artery bypass grafting. ${ }^{1}$ However, Finn and associates ${ }^{2}$ compared interleukin- 8 levels in pediatric patients undergoing either $\mathrm{CPB}$ or neurosurgical intervention after similar anesthesia induction and found that "post-CPB factors" are more important to induce interleukin-8 release.

For further exploration of the mechanism involved, it is necessary to identify the primary source of these cytokines. We recently measured the plasma levels of these cytokines simultaneously in the peripheral arterial blood, the coronary sinus blood, and the mixed venous blood in patients undergoing CPB. Our data indicated that the heart, but not the lung, is a major source of tumor necrosis factor- $\alpha$ and interleukin- $6 .^{3}$ The myocardium may also be an important origin of interleukin- 8 during reperfusion after more severe injury. ${ }^{3,4}$ In contrast, neither the heart nor the lung is the main source of interleukin-10. ${ }^{3}$

Nevertheless, we agree that some pre-CPB factors may also play a role in influencing cytokine responses associated with CPB. In another recent study, we ${ }^{5}$ found that steroid administration before operation can significantly inhibit tumor necrosis factor- $\alpha$ and interleukin- 8 release but greatly enhance interleukin-10 production. Such a "priming effect" is certainly interesting and needs to be further investigated.

Song Wan, $M D^{a}$

Jean-Louis LeClerc, $M D^{a}$

Jean-Marie DeSmet, $M D^{a}$ Jean-Louis Vincent, $M D, P h D^{b}$ Department of Cardiac Surgery ${ }^{a}$ Department of Intensive Care ${ }^{b}$ University Hospital Erasme Free University of Brussels Brussels, Belgium

\section{REFERENCES}

1. Wan S, Marchant A, DeSmet JM, Antoine M, Zhang H, Vachiery J-L, et al. Human cytokine responses to cardiac transplantation and coronary artery bypass grafting. J Thorac Cardiovasc Surg 1996;111:469-77.

2. Finn A, Naik S, Klein N, Levinsky RJ, Strobel S, Elliott M. Interleukin-8 release and neutrophil degranulation after pediatric cardiopulmonary bypass. J Thorac Cardiovasc Surg 1993; 105:234-41.

3. Wan S, DeSmet JM, Barvais L, Goldstein M, Vincent JL, LeClerc JL. The myocardium is a major source of proinflammatory cytokines in patients undergoing cardiopulmonary bypass. J Thorac Cardiovasc Surg. In press.

4. Oz MC, Liao H, Naka Y, et al. Ischemia-induced interleukin-8 release after human heart transplantation: a potential role for endothelial cells. Circulation 1995;92(Suppl):II428-32.

5. Wan S, DeSmet JM, Antoine M, Goldman M, Vincent JL, LeClerc JL. Steroid administration in heart and heart-lung transplantation: Is the timing adequate? Ann Thorac Surg 1996;61:674-8.

$12 / 8 / 74332$ 